\title{
AN ATTEMPT TO ANALYZE THE CONSTITUTION OF THE CHROMOSOMES ON THE BASIS OF SEX- LIMITED INHERITANCE IN DROSOPHILA
}

\author{
T. H. MORGAN \\ From the Zoological Laboralory, Columbia University \\ FOUR FIGURES-COLOR PLATE
}

In several preliminary notes I have given a brief account of the origin of four mutations in the eye-color of the fly, Drosophila ampelophila. The heredity of these eye-colors may now. be given in full, and the bearing of the results, on sex-limited inheritance in general, discussed. In addition to the eye-color data I shall also describe a few cases in which two other sexlimited characters have been studied in connection with eyecolor, namely: short proportionate wings and yellow body-color. A full account of the heredity of these latter two characters will be reserved, however, for later publication. Here they are used only in so far as they give an opportunity to study the mode of inheritance of three sex-limited characters present in one individual. ${ }^{1}$

The experiments on Drosophila have led me to two principal conclusions:

FIRsT, that sex-limited inheritance is explicable on the assumption that one of the material factors of a sex-limited character is carried by the same chromosomes that carry the material factor for femaleness.

SECOND, that the 'association' of certain characters in inheritance is due to the proximity in the chromosomes of the chemical substances (factors) that are essential for the production of those characters.

${ }^{1}$ The facts here recorded were first announced in a public lecture given in the Marine Biological Laboratory at Woods Hole, Mass., July 7, 1911. 


\section{PART I}

THE HEREDITY OF RED, VERMILION (OR BRIGHT-RED), PINK, AND ORANGE EYES

The eyes of the wild fly are dull red, and may be designated by the letter $R$. The bright-red eye is vermilion in color and is indicated by $\mathrm{V}$ in the tables.

The pink eye is more translucent than the red eye, but of about the same general tone. It lacks the dark fleck seen in the red and vermilion eye when the eye is examined with a lens. This black fleck changes its position as the lens travels over the eye. The pink eye, $\mathrm{P}$, is with a little experience easily distinguished from the other colors, especially in newly hatched flies. When the fly gets old the eye turns to a brown color very characteristic of this type of eye.

The orange is the faintest eye color in the series. If the fly is very small it may be only tinged with orange. If the fly is large (coming from a well-fed maggot) the orange eye, $\mathrm{O}$, is deep orange in shade; and without some experience it may be confused with the pink eye, especially if a mixed culture containing flies of different ages and sizes is examined. A little experiencewill soon make one familiar with the difference between these two colors.

I do not hesitate to state that there are no intergrades between these eye-colors. Each color is distinct and breeds true to its kind. Moreover, the heterozygous flies show the dominant color. One 'dose' is indistinguishable from two doses of the color determiner.

In making the matings and recording the numbers $I$ have been assisted in the experiments with eye-color by Miss Eleth Cattell; and in the experiments in sex-limited inheritance for three factors by Miss E. M. Wallace and by Miss M. B. Abbott. I wish to express here my appreciation of the assistance that they have given. I have discussed the theoretical results of the eyecolor inheritance with Mr. A. H. Sturtevant, as the work went on. 
and this discussion has been helpful to me in finding suitable formulae for the data.

Rather than defer the discussion of the interpretation of the results to the end of the account I will take up each case in turn. A few words will suffice to make clear the symbolism used. The red eye of the wild fly seems to contain three pigments: red, pink, and orange. The mutants have arisen by the loss in turn of one of the factors that make possible the development of the red color. If these three colors (or the factors that stand for them) are represented by the symbols $\mathrm{R}, \mathrm{P}$, and $\mathrm{O}$, then the red eye is $\mathrm{RPO}$, the pink eye is rPO, the orange eye is rpO. Obviously there is another combination possible, viz: the loss of the pink factor and the retention of $\mathrm{R}$ and $\mathrm{O}$, giving $\mathrm{RpO}$, which is the formula for the bright red or vermilion eye. The matter may be better expressed in another way. Should from any cause whatsoever the factor for pink $(\mathrm{P})$ drop out, vermilion $(\mathrm{RpO})$ would appear. If, on the other hand, the red factor $(\mathrm{R})$ should be lost from the red-eyed fly, pink would result (rPO). By crossing a vermilion fly with a pink one, some orange-eyed flies (rpO) would appear in the second (inbred) generation by recombination.

In the formulae that follow it is always assumed that one dose of red or pink gives the same result as do two doses, which accords with the facts.

It is necessary to say a word in advance about sex determination in these flies. I assume that every egg after eliminating its polar bodies, contains the sex chromosome, called X. Prior to their extrusion the egg, like all the other cells of the female, contains two X's or XX. The male cells contain one X. Half the spermatozoa contain one $\mathrm{X}$, the other half lack X. Miss N. M. Stevens has shown that these relations are actually present in Drosophila. The peculiar 'coupling' of $\mathrm{X}$ with the factor for pink, that runs through the formulae and gives the significant results connected with sex-limited inheritance, will be discussed later. 
Red eye by vermilion eye

When red-eyed females were crossed with vermilion-eyed males all the offspring (93 in number) were red. These inbred produced in the second generation red females, red males, and vermilion males. The result shows that vermilion is sex-limited. The following table gives the results and numerical data:

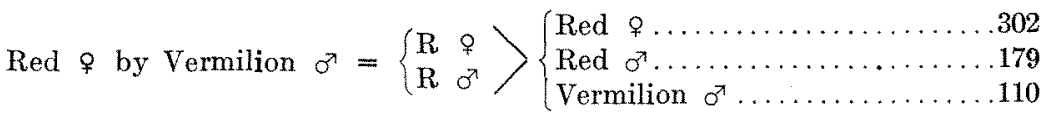

The two classes of males taken together number 289 , which is a close approximation to the 302 red females. The results may. be accounted for in the following way:

$$
\begin{aligned}
\text { Red } q & =\text { RPOX }- \text { RPOX } \\
\text { Vermilion } \sigma^{x} & =\operatorname{RpOX}-\operatorname{RpO}
\end{aligned}
$$

\begin{tabular}{|c|c|c|}
\hline$F_{1}$ & Red $\%$ & RPOXRpOX \\
\hline & $\operatorname{Red} \sigma^{7}$ & RPOXRpO \\
\hline Gametes of $\mathrm{F}_{1}$ & $\begin{array}{l}\text { Red } \% \\
\text { Red o }\end{array}$ & $\begin{array}{l}\text { RPOX - RpOX } \\
\text { RPOX - RpO }\end{array}$ \\
\hline
\end{tabular}

$\begin{array}{llr} & & \\ & \text { RPOXRPOX } & \text { Red } \% \\ F_{2} \text { Generation } & \text { RPOXRpOX } & \text { Red } \% \\ & \text { RPOXRpO } & \text { Red o } \\ & \text { RpOXRpO } & \text { Vermilion o }\end{array}$

It will be noted that the red females belong to two classes, one pure, the other heterozygous: the red male is also heterozygous, while the vermilion male is pure.

The reciprocal cross, namely, red male by vermilion female gives red females and vermilion males. In other words the daughters are like the father and the sons like the mother. This gives what $I$ call criss-cross inheritance. When these $F_{1}$ 's are inbred they give red males and females and vermilion males and females as shown in the next table. 


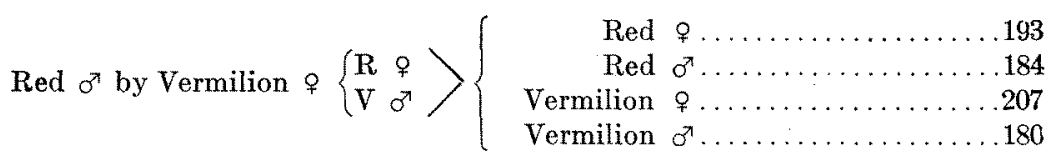

The two preceding crosses are typical for all cases of sexlimited inheritance in Drosophila, and for some, perhaps for all, other cases. They may be summed up in the statement that where in one combination a character in the grandfather is transmitted to his grandsons alone, the reciprocal combination gives criss-cross inheritance.

The number of males and of females in each class is approximately equal in the $\mathrm{F}_{2}$ generation. The results are accounted for as follows:

$$
\begin{aligned}
\text { Vermilion } & \text { RpOX } \\
\text { Red or } & \text { RPOX - RpOX }
\end{aligned}
$$

\section{$F_{1}$}

Gametes of $\mathbf{F}_{1}$
Red $\&$ RpOXRPOX

Vermilion ơ RpOXRpo

$\mathrm{F}_{2}$ Generation

$\begin{array}{lc}\text { RpOXRpOX } & \text { Vermilion }{ }^{+} \\ \text {RPOXRpOX } & \text { Red }{ }^{\circ} \\ \text { RpOXRpO } & \text { Vermilion } \sigma^{\circ} \\ \text { RPOXRpO } & \text { Red or }\end{array}$

\section{Red eye by pink eye}

The results of this cross have been already published (Science, 1911), but the hypothetical explanation not given. For the sake of completeness the facts must be restated here. Red female by pink male gave red male and red female offspring. These inbred gave in the $\mathrm{F}_{2}$ generation 3063 red males and females and 169 pink males and females. 


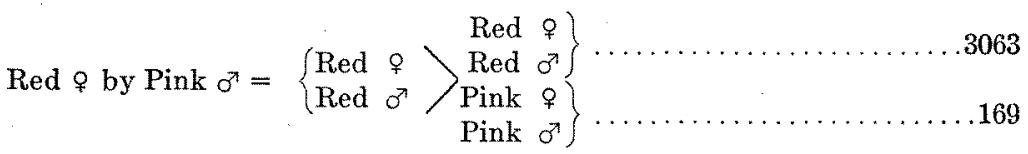

In this case there is no sex-limited inheritance. An analysis of the result, based on the same formulae, gives the following:

Red $\%$ RPOX - RPOX

Pink of rPOX - rpO

$\begin{array}{lll}F_{1} & \text { Red } \% & \text { RPOXrPOX } \\ \text { Red } 0^{7} & \text { RPOXrpO }\end{array}$

Gametes of $F_{1}$

Red $q$ RPOX - rPOX

Red of RPOX - rPOX - RpO - rpO

$\mathrm{F}_{2}$

\begin{tabular}{|c|c|}
\hline $\begin{array}{l}\text { RPOXRPOX } \\
\text { RPOXrPOX } \\
\text { rPOXRPOX }\end{array}$ & 3 red $\%$ \\
\hline rPOXrPOX & 1 pink \& \\
\hline $\begin{array}{l}\text { RPOXRpO } \\
\text { RPOXrpO } \\
\text { rPOXRpO }\end{array}$ & 3 red \\
\hline rPOXrpO & 1 pink \\
\hline
\end{tabular}

The expectation is three times as many red females as pink females, and three times as many red males as pink males. The actual ratio is about 20 to 1 , taking the two sexes together. Thus while all the classes are represented, and the reds in excess of the pinks, they are much more numerous than expectation. The cause of this deficit in the pinks will be discussed later when other similar results can be brought forward.

The reciprocal cross, red males and pink females, gave in the first generation red males and females. These produced in the $\mathrm{F}_{2}$ generation red males and females, and pink males and females in the proportions shown in the next table. 


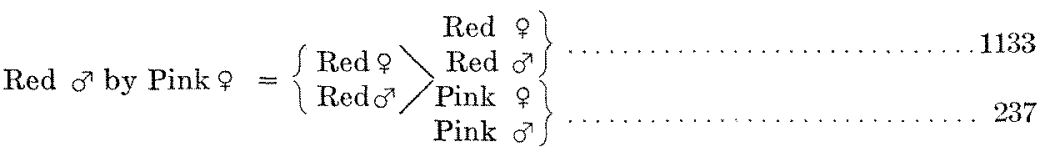

The analysis of the result, based on the same formulae, is as follows:

Pink of rPOX - rPOX

Red or RPOX - RpO

$\mathrm{F}_{1} \quad$ Red o rPOXRPOX

Red or rPOXRpO

Gametes of $F_{1} \quad$ Red $\%$ rPOX - RPOX

Red or $r P O X-R P O X-i p O-R p O$

\begin{tabular}{|c|c|}
\hline & Pinl \\
\hline & $D_{1}$ \\
\hline & sed \\
\hline RPOXRPOX & Re \\
\hline POXrpO & Pin \\
\hline POXRpO & \\
\hline RPOXrp & \\
\hline & \\
\hline
\end{tabular}

In this combination also the expectation is three red females to one pink female and three red males to one pink male, while the realization is about 5 to 1 for all reds versus all pinks.

Red eye by orange eye

When red-eyed females are crossed with orange-eyed males all of the offspring have red eyes. These inbred produce redeyed males and females, pink-eyed males and females, and vermilion-eyed males and orange-eyed males. No females with vermilion or with orange eyes appear in the second generation. Here two characters are, in a sense, sex-limited, although the parents showed only one of them, viz., the orange. 


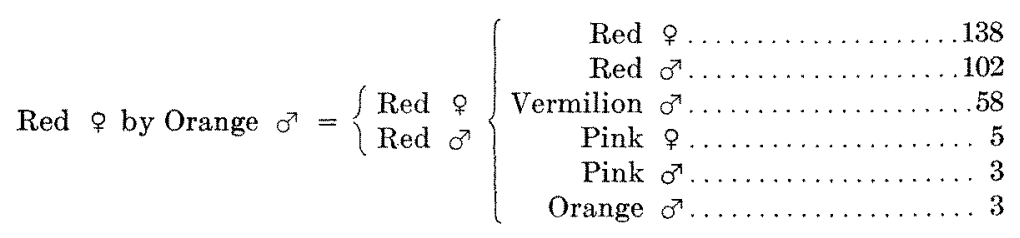

The number of pinks and oranges is very small, although the other classes contain a fair number of offspring. The analysis follows:

Red o RPOX - RPOX

Orange or rpOX $-\mathrm{rpO}$

$F_{1}$

Red o RPOXrpOX

Red $\sigma^{\pi}$ RPOXrpC

Gametes of $F_{1}$

Red 9 RPOX - rPOX - RpOX - rpOX

Red ${ }^{\circ}$ RPOX - rPOX - RPO - rpO

$\mathrm{F}_{2}$

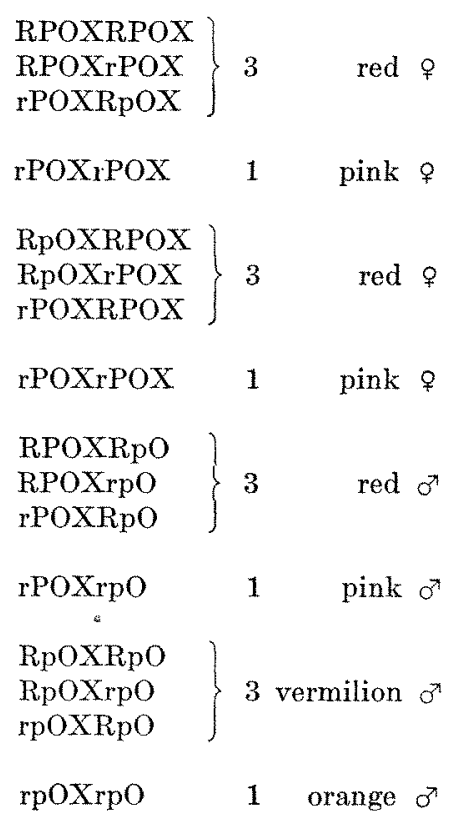


In this case the expectation was far ahead of the realization; for, while the red females to the pink females are estimated as 3 to 1 they are as 37 to 1 in the actual count. Again the vermilioneyed males should be as numerous as the red males, but they are not half as numerous. Thus while the formulae give the classes actually realized in the experiment with the sexes properly distributed-a matter of no small complexity-yet the numerical results are by no means the expected ones.

The reciprocal cross, red males by orange females, gives red females and vermilion males. These inbred produce eight classes in the second, or $\mathrm{F}_{2}$, generation. These eight classes represent, in fact, the whole gamut of eye-colors.

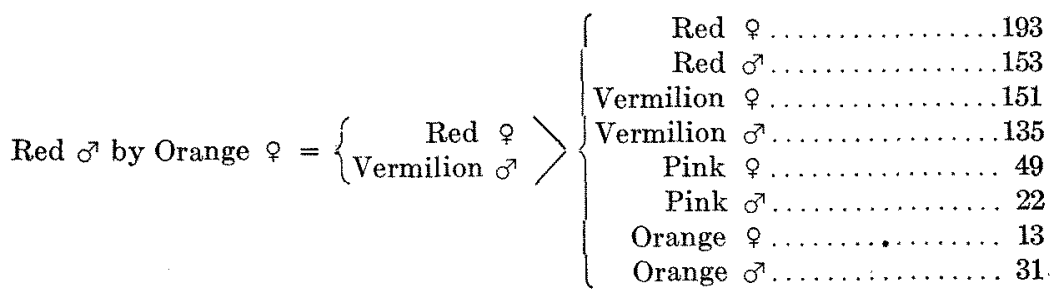

In this combination the number of pinks and oranges is by no means so small as in the preceding case, although the other colors are not much more numerous than before. The analysis is as follows: 
$F_{1}$

Red o rpOXRPOX

Vermilion of rpOXRpO

Gametes of $\mathbf{F}_{1}$

Red \& rpOX - RPOX - RpOX - rPOX

Vermilion of rpOX - RpOX $-\mathrm{RpO}-\mathrm{rp} . \mathrm{O}$

$F_{\text {。 }}$

\begin{tabular}{|c|c|}
\hline rpOXrpOX & Orange \\
\hline $\operatorname{rpOXRpOX}$ & Vermilion \\
\hline RPOXrpOX & Red \\
\hline RPOXRpOX & Red \\
\hline RpOXrpOX & Vermilion \\
\hline RpOXRpOX & Vermilion \\
\hline rPOXrpOX & Pink \\
\hline rPOXRpOX & Red \\
\hline rpOXRpO & Vermilion \\
\hline rpoXrpO & Orange \\
\hline RPOXRpO & Red \\
\hline RPOXrpO & Red \\
\hline RpOXRpO & Vermilion \\
\hline RpOXrpo & Vermilion \\
\hline rPOXRpO & Red \\
\hline rPOXrpO & Pink \\
\hline
\end{tabular}

The expectation in the $\mathrm{F}_{2}$ generation is 3 reds, 3 vermilion, 1 pink, 1 orange. The numbers realized are somewhat in this same ratio, except that the pinks and the oranges again run behind their schedules. A curious, and I think significant, relation will be observed between the sexes in the last two classes; for, the pink females are twice as numerous as the pink males, while the reverse holds for the orange-eyed flies. The same relation comes up again in the pink-male by orange-female cross to be described later. 
This completes the crosses between red and the other colors. We may now take up the remaining combinations. It will be noted that from now on the results are about an exact duplication of the series just described. The results may be said to be mirror figures of each other which suggests the fanciful idea that the combinations of colors, that the tables represent, have some such stereometric relation.

\section{Vermilion eye by pink eye}

When a vermilion-eyed female is crossed with a pink-eyed male, all the female offspring are red, and all the male offspring are vermilion. These inbred produce in the second generation all four classes of both sexes:

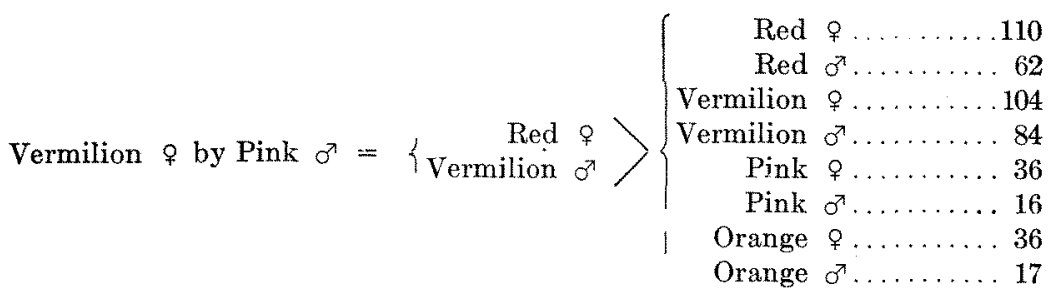

A deficiency in the males of every class is noticeable in this cross. The total of all the females is 286 and of all the males 179 , nearly 2 to 1 . The analysis, as shown in the next table, calls of course for equal numbers. 
Vermilion $\&$ RpOX - RpOX

Pink or $\mathrm{rPOX}-\mathrm{rpO}$

$F_{1}$

Red o RpOXrPOX

Vermilion of RpOXrpO

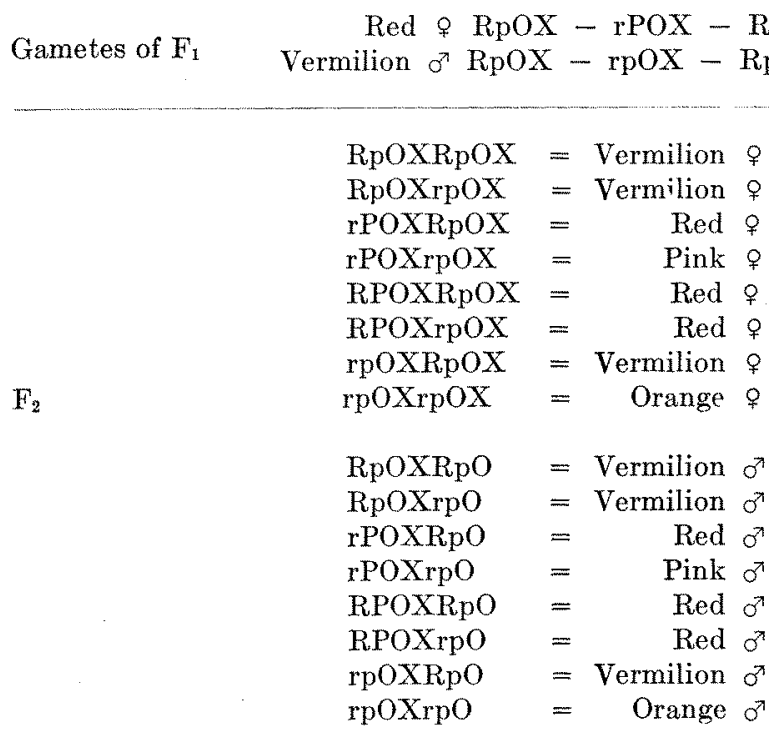

The expectation both for males and females is 3 red, 3 vermilion, 1 pink, 1 orange. The females give approximately this result, while the males fall below the expectation, especially the pink and orange males.

The reciprocal cross, vermilion male by pink female, gives all red offspring. These inbred give for the $F_{2}$ generation red males and females, vermilion males, pink males and females, orange males. Here again a case of double sex-limited inheritance occurs, and of course in the same colors, vermilion and orange, as before.

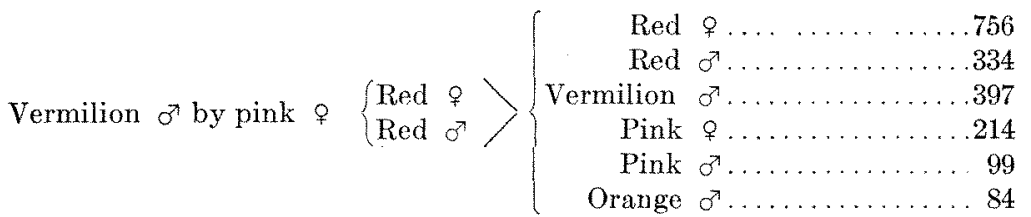


The numbers are relatively high in this experiment, and significant. The red and the vermilion males taken together give approximately the same number as the red females. Similarly the pink and the orange males, taken together, are nearly as numerous as the pink females. The following table shows what the expectation is in regard to these numbers:

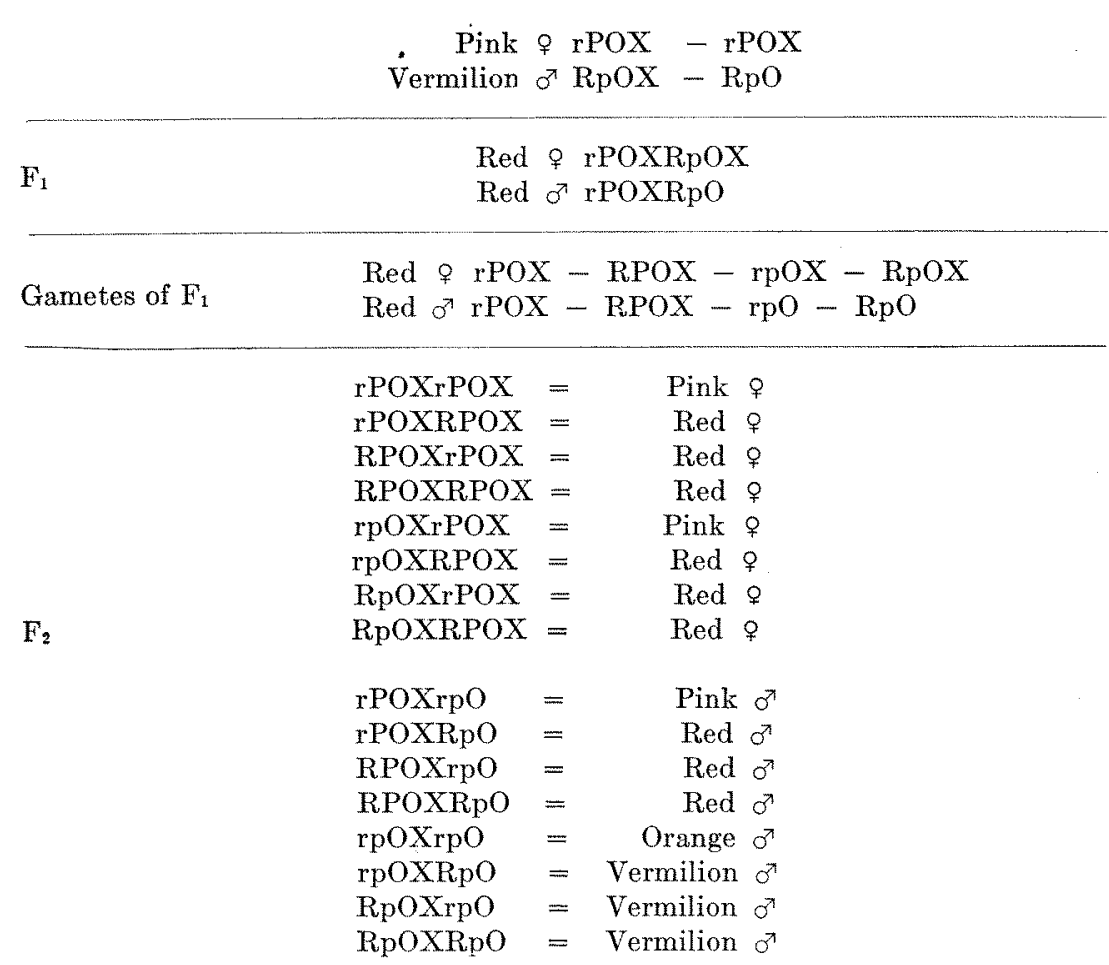

The preceding analysis shows that there should be three times as many red females as pink females. There are, in fact, somewhat more than three times as many. The pink males should be to the red males (or to the vermilion) as 1 to 3 . They do not come up to this ratio but nearly approximate to it. Similarly for the orange males. In this instance, where the numbers are large, it is quite apparent that the expected and the realized results fairly agree. The failure is here again obviously due to a reduction in the number of the pink and orange classes. 


\section{Vermilion eye by orange eye}

When a female with vermilion eyes is bred to a male with orange eyes, all of the offspring are vermilion eyed. These inbred produce the two grand-parental colors in males and in females.

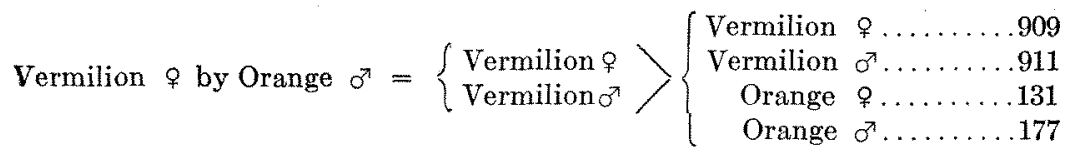

The one point to notice here is the excess of orange males over orange females that has occurred in all of the preceding cases where both classes occur. The absence of red and of pink from the combination is due of course to the absence of pink in both parents.

$$
\begin{gathered}
\text { Vermilion } \& \text { RpOX }-\operatorname{RpOX} \\
\text { Orange }{ }^{\pi} \operatorname{rpOX}-\operatorname{rpOX}
\end{gathered}
$$

$\begin{array}{ll}\text { Fi } & \text { Vermilion o RpOXrpox } \\ \text { Vermilion of RpOXrpOX }\end{array}$

Gametes of $\mathrm{F}_{1}$

$$
\begin{aligned}
& \text { Vermilion o RpOX - rpOX } \\
& \text { Vermilion of RpOX - rpOX - RpO - rpO }
\end{aligned}
$$

$\left.F . \quad \begin{array}{l}\text { RpOXRpOX } \\ \text { RpOXrpOX } \\ \text { rpOXRpOX }\end{array}\right\} 3$ vermilion $q$

The analysis calls for 3 vermilion females to 1 orange female. In fact, $5 \frac{1}{2}$ times as many vermilion as orange females are found and the same disproportion, due to deficiency in orange, is found also in the male classes. 
The reciprocal cross, vermilion male by orange female, gives also all vermilion offspring. These inbred give both original classes in both sexes.

$$
\text { Vermilion } \sigma^{\pi} \text { by Orange } q=\left\{\begin{array} { l } 
{ \text { Vermilion } q } \\
{ \text { Vermilion } o ^ { 7 } }
\end{array} \left\{\begin{array}{r}
\text { Vermilion } q \ldots . .411 \\
\text { Vermilion } \sigma^{7} \ldots . .330 \\
\text { Orange } o \ldots .50 \\
\text { Orange } \sigma^{7} \ldots \ldots .62
\end{array}\right.\right.
$$

Here a slight excess of orange males over orange females occurs. The relation of vermilion to orange is seen in the following analysis.

$$
\begin{array}{cll}
\text { Orange } & \text { rpOX } & \text { rpOX } \\
\text { Vermilion }{ }^{7} & \operatorname{RpOX}-\mathrm{RpO}
\end{array}
$$

$\mathrm{F}_{1}$

Vermilion $q$ rpOXRpOX

Vermilion $\sigma^{7}$ rpOXRpO

Gametes of $\mathbf{F}_{1}$

$$
\begin{array}{ll}
\text { Vermilion of } & \operatorname{rpOX}-\operatorname{RpOX} \\
\text { Vermilion of } & \text { rpOX }- \text { RpOX - rpO - RpO }
\end{array}
$$

$\mathrm{F}_{2}$

$$
\begin{aligned}
& \operatorname{rpOXrpOX}=1 \text { orange } \odot \\
& \left.\begin{array}{l}
\text { rpOXRpOX } \\
\text { RpOXrpOX } \\
\text { RpOXRpOX }
\end{array}\right\}=3 \quad \text { vermilion } \circ
\end{aligned}
$$

$$
\begin{aligned}
& \left.\begin{array}{l}
\text { rpOXrpo } \\
\text { rpOXRpO } \\
\begin{array}{l}
\text { RpOXrpo } \\
\text { RpOXRpO }
\end{array}
\end{array}\right\}=3 \quad \text { vermilion or }
\end{aligned}
$$

The expectation is for three vermilion females to one orange female: the actual numbers are 8 to 1 . The same expectation holds for the male while the actual numbers give $5 \frac{1}{2}$ to 1 . 


\section{Pink eye by orange eye}

When a pink-eyed female is paired with an orange-eyed male, all of the offspring are pink. These inbred produce pink males and females and orange males.

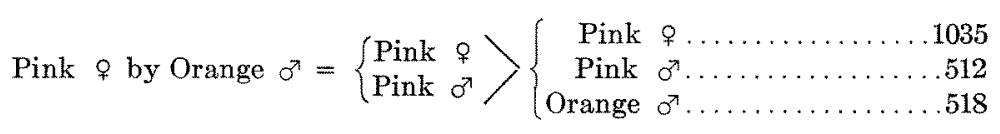

The two classes of males taken together give almost exactly the same number as the females. Both pink and orange males occur in equal numbers. In this experiment there appeared 15 orange females (not given in the table). This is possibly due to further mutation in the hybrid or to some error. The formulae are as follows:

$$
\begin{array}{cl}
\text { Pink o } & \text { rPOX - rPOX } \\
\text { Orange of } & \text { rpOX - rpO }
\end{array}
$$

$\mathrm{F}_{1}$

Pink of rPOXrpOX

Pink or $o^{t}$ POXrpO

Gametes of $F_{1}$

\begin{tabular}{|c|c|c|}
\hline \multirow{4}{*}{$\mathrm{F}_{2}$} & rPOXrPOX & Pink 9 \\
\hline & rpOXrPOX & Pink o \\
\hline & rPOXrpO & Pink or \\
\hline & rpoXrpO & Orange $\sigma^{r}$ \\
\hline
\end{tabular}

Pink of rPOX - rpOX

Pink of rPOX - rpO

The reciprocal cross, pink males by orange females, gives the criss-cross inheritance, viz., pink females and orange males. It is of interest to note in passing that there were 233 pink females and 215 orange males recorded in this $\mathrm{F}_{1}$ generation, showing that in the direct cross the sexes of opposite colors appear in nearly equal numbers. In the second generation both colors in males and females occur. 


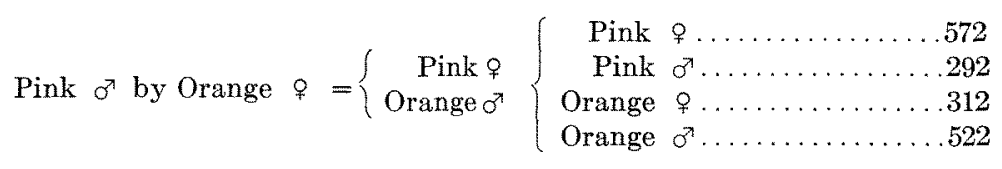

In the $F_{2}$ generation a peculiar relation becomes apparent: there are one half as many pink males as pink females, while in the orange class the females are only a little more than half as numerous as the males. Thus while the total number of females of both classes (884) is nearly the same as the total number of the males when both classes are added together (814), yet this approximate equality is due to the reverse ratio of the sexes in the two color classes. It is worth noting, too, that this relation exists in the same group, in which as stated above, the pink females and orange males existed in equal numbers in the $F_{1}$ generation. In fact, it is just these two classes that still exist in equal numbers in the $F_{2}$ generation that give the significance to these results.

The analysis of this case is as follows:

\begin{tabular}{|c|c|c|}
\hline & $\begin{array}{r}\text { Orange } \circ \\
\text { Pink of }\end{array}$ & $\begin{array}{l}\operatorname{rpOX}-\operatorname{rpOX} \\
\operatorname{rPOX}-\operatorname{rpO}\end{array}$ \\
\hline$F_{1}$ & 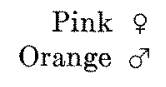 & $\begin{array}{l}\text { rpOXrPoX } \\
\text { rpOXrpo }\end{array}$ \\
\hline Gametes of $F_{1}$ & 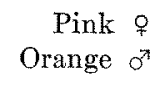 & $\begin{array}{l}\text { rpOX }-\mathrm{rPOX} \\
\operatorname{rpOX}-\mathrm{rpO}\end{array}$ \\
\hline $\mathrm{F}_{\Omega}$ & $\begin{array}{l}\text { rpOXrpOX } \\
\text { rPOXrpoX } \\
\text { rpOXrpO } \\
\text { rPOXrpO }\end{array}$ & $\begin{array}{r}\text { Orange } q \\
\text { Pink } q \\
\text { Orange } 0^{7} \\
\text { Pink } \sigma^{7}\end{array}$ \\
\hline
\end{tabular}

At present I can offer no reasonable explanation of this peculiar relation between color and sex as shown in this experiment. It appears to be related to facts to be described later in connection with associative inheritance, and it is probably also related to a change in the sex-ratio that I have recorded in another cross (see Proc. Soc. Exp. Biol. and Med., 1911). As I have these problems still under investigation I shall not discuss them further here. 


\section{Discussion of results on eye-color}

An examination of the formulae used to interpret the preceding results will show three points of importance. First, that the red factor $\mathrm{R}$ may be present in the male-producing sperm. It is present there, in fact, if the fly has either red or vermilion eyes.

Second, the factor for pink is only present when $\mathrm{X}$ or the sex factor is present. It is absent, therefore, from all male-producing sperm. It is true that $\mathrm{X}$ may exist without the pink factor, as in the vermilion and orange flies that owe their peculiarity to the absence of $P$. If the $P$ is contained in $X$, as its connection with sex establishes, then its absence must be due to its loss from $X$. Consequently while $\mathrm{X}$ may exist without $\mathrm{P}$, the latter, $\mathrm{P}$, can occur only when $X$ is present.

Third, the factor for orange, $O$, is present in every case. It might, therefore, be omitted from all of the formulae without affecting the results, provided the absence of $R$ and of $P$ be assumed to give $\mathrm{O}$. But since orange is a definite color the absence of red and pink can not be assumed to leave orange. For this reason I have always inserted it. Its location can not be identified because it seems never to be lost. I shall give my reasons later for not identifying it with the color-producer C.

The facts here recorded for the factor $\mathrm{P}$ amount in my opinion to a demonstration that this factor is intimately associated with the factor for sex. All of the 58 classes found in the second filial generation can beaccounted for on the assumption that $X$ contains $\mathrm{P}$, when $\mathrm{P}$ is present; and, as I pointed out in connection with the heredity of white eyes versus red eyes, sex-limited inheritance can be explained by assuming that $\mathrm{X}$ carries red if red is present. In the case of vermilion and of orange eyes pink is lost from $\mathrm{X}$ and the formulae give the classes realized. The asymmetrical distribution of pink follows the same law as the asymmetrical distribution of the sex chromosomes.

A study of the formulae also reveals the fact that in the male of these classes (red and pink) when pink is present in the simplex condition (it can not occur otherwise in the male) no interchange takes place between the pink element contained in the X-chromo- 
some and any other chromosome, because, as I have previously pointed out, the sex chromosome in the male has no mate. Consequently no such interchange of chromatic particles, as we must assume possible for the other chromosomes, is here possible. The entire scheme of sex-limited inheritance rests, as I have tried to show, on this simple basis. To prevent a possible misunderstanding I may point out that the behaviour of the $\mathrm{R}$-factor illustrates how an interchange of $R$ and no $R$ is possible in the male. If the $\mathrm{R}$ is contained in some other chromosome in the heterozygote it may interchange position with its absent condition in a corresponding position or particle in the mate of this chromosome.

The facts here recorded for the inheritance of pink make out a strong case in favor of the view that sex-limited inheritance can be explained if we locate the factor for pink in one of the sex chromosomes. I have pointed out that a similar assumption explains the heredity of white eyes, also sex-limited. I can state that the same assumption will accountfor theinheritance of yellow color and for the two wing mutations that are sex-limited. More important still is the fact that the extremely complicated results that follow when two or more of these sex-limited characters are combined must also be explained on the same principle. It is this evidence that has convinced me that segregation, the key note to all Mendelian phenomena, is to be found in the separation, during the maturation of the egg and sperm, of material bodies (chemical substances) contained in the chromosomes.

This conclusion need not mean that the material bodies present in the chromosomes are the substances out of which the unit-characters are built up. On the contrary all that this evidence goes to show is that the bodies represent some material necessary for the development of the particular character in question, and it is certain that other parts of the cell also contribute to the elaboration of the unit-character. This is the view I should adopt, provisionally, as the more probable. We see, in fact, that the red color of the eye of the wild fly is due to the collaboration of at least four different factors in the cell, namely, a red, a pink, and an orange determiner, and a color producer. The pink determiner and the color producer are carried by the 
X-chromosome, but are not otherwise related. The red factor is contained in some other chromosome; the orange factor we can not yet locate.

Concerning the chemical nature of the three colors I have no facts to offer. That they may be related chemically is made probable by the evidence, to be given later, that they are all three activated by the same color-producer $\mathrm{C}$. If this is admitted we see that similar substances may be contained in different chromosomes, and the further conclusion is then near at hand that in some cases the same substance may be carried by more than one chromosome. In connection with a mode of inheritance that is not as yet clearly Mendelian, viz., beaded and truncated wings I shall examine this assumption further, but it is not needed for the cases here described that follow Mendel's law for one pair of factors.

In the application of the Mendelian formulae to the $\mathrm{F}_{2}$ generation it has been only too often apparent that while the formulae give in all cases the expected classes, yet the numerical results depart widely from expectation. A consideration of the facts will bring conviction to anyone, I think, that the numerical departures from expectation are due to special, disturbing factors. At another time, when I am able to present other data for wing inheritance, and for disturbances in the sex ratios, I shall take up the question of these irregularities more fully. Here I can only point out one or two possibilities. In some cases the disturbance can be traced directly to the principle of 'association.' By this I mean that during segregation certain factors are more likely to remain together than to separate, not because of any attraction between them, but because they lie near together in the chromosomes, as will be explained more fully later. For example, when red $\circ$ RPOX is crossed with pink or rPO the offspring are red $\%$ RPOXrPOX and red or RPoXrpO. As shown by the analysis on page 370 there are four classes of spermatozoa possible, but if $\mathrm{R}$ and $\mathrm{P}$ tend to hold together ${ }^{2}$ rather than interchange with $\mathrm{r}$ there will be more female-producing sperm RPOX than rPOX,

${ }^{2}$ In reality $\mathrm{C}$ and $\mathrm{P}$. 
and hence proportionately more reds in relation to pink than random or Mendelian segregation demands. The same principle applied to other cases will often account for the disturbances in the Mendelian ratios.

It is evident, however, that other conditions also may be responsible for the irregular ratios. The fact that the low types of mutants-those that have lost two factors, for example-fall short of expectation as compared with the normal type, and the disturbances in the sex ratios call perhaps for a different explanation. In regard to the former it is probable either that gametes containing certain combinations are less likely to fertilize or be fertilized or that the product of such fertilization is less viable. Until certain work is completed that I have on hand there is no need to attempt to decide which of the suppositions is the correct one. 
THE RELATION OF THE COLOR PRODUCER C TO THE COLOR DETERMINERS OF EYE COLOR

In a preceding paper (Science, July 1910) dealing with sexlimited inheritance of white eyes I have shown how the results are explicable on the assumption that the factor for red color is absent from the $\mathrm{X}$-chromosome in the white-eyed individuals. It may appear that this assumption flatly contradicts the assumption made in the preceding cases for eye-color in which it is shown that the factor (a factor!) for red $R$ is present in the male-producing sperm (when red is present at all). There is no contradiction, however, for it is not the color determiner $R$ that is present in the $\mathrm{X}$-chromosome, but the color-producer $\mathrm{C}$. It is the absence of $\mathrm{C}$ from $\mathrm{X}$ that gives the white-eyed fly whose formula is cRPO. For the sake of simplicity I have not introduced this relation in the preceding examples. The change, if introduced, gives precisely the same results, but adds another letter.

I purpose now to consider the relation of this $\mathrm{C}$ factor to the eye colors. It may make the case simpler if first an example for white and red is given.

When a white-eyed maie is crossed to a red female the offspring are red. These inbred give red females (50 per cent), red males (25 per cent), and white males ( 25 per cent). The formulae are as follows:

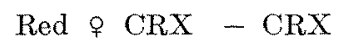

$\mathrm{F}_{2} \quad \begin{aligned} & \text { CRXCRX } \\ & \text { CRXcRX }=\text { Red } q \\ & \text { CRXcR }=\text { Red } 0^{7} \\ & \text { cRXcR }=\text { White } 0^{7}\end{aligned}$

The converse cross, white female by red male, gives red females and white males. These inbred give red males and females and 
white males and females. The formulae for this case are as follows:

$$
\text { White } \% \text { cRX }-\mathrm{cRX}
$$

Red ${ }^{\top}$ CRX - cR

F1 $\begin{array}{rl}\text { Red } q & \mathrm{cRX}-\mathrm{CRX} \\ \text { White } \sigma^{\prime} & \mathrm{cRX}-\mathrm{cR}\end{array}$

$\mathbf{F}_{2} \quad \begin{aligned} \text { cRXcRX } & =\text { White } q \\ \text { CRXcRX } & =\text { Red } q \\ \text { cRXcR } & =\text { White } \sigma^{7} \\ \text { CRXcR } & =\text { Red } \sigma^{7}\end{aligned}$

These two examples will serve to show the method by which all the white-red combinations can be treated. The results are those that I have already published (Science, 1910, vol. 32).

\section{Pink eye by white eye}

The results of this combination have been already given (Science, 1911). Since the numerical relations were peculiar I repeated the experiment and obtained large numbers of individuals that furnish a better basis for interpretation. When a pink-eyed female is bred to a white-eyed male all the offspring have red eyes. These inbred produce red-, white-, and pinkeyed offspring in the following proportions:

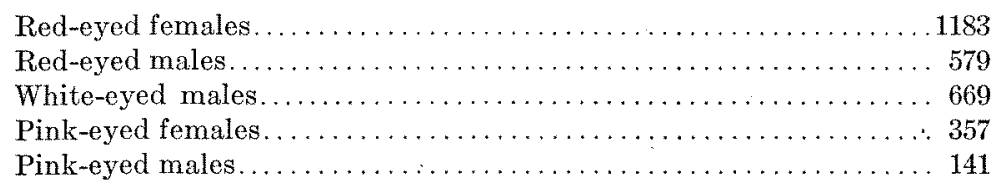

If we interpret these results in the same terms as those used for white and red we get the following formulae. Since the orange factor is present throughout and the orange eye is not involved $\mathrm{O}$ is omitted. The white-eyed male came from red stock through the loss of $\mathrm{C}$ and his formulae is $\mathrm{cRP}+\mathrm{cR}$. 


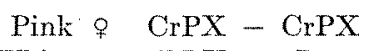

$F_{1} \quad \begin{array}{lll}\text { Red } \% & \text { CrPXcRPX } \\ \text { Red } \sigma^{7} & \text { CrPXcR }\end{array}$

$\begin{array}{ll}\text { Cametes of } \mathrm{F}_{1} & \text { Red o CrPX }-\mathrm{crPX}-\mathrm{cRPX}-\mathrm{CRPX} \\ & \text { Red } \sigma^{7} \mathrm{CrPX}-\mathrm{CRPX}-\mathrm{cR}-\mathrm{cr}\end{array}$

\begin{tabular}{|c|c|c|c|}
\hline & CrPXCrPX & $=$ & Pink $\%$ \\
\hline & CrPXerPX & $=$ & Pink $q$ \\
\hline & CrPXeRPX & $=$ & Red $q$ \\
\hline & CrPXCRPX & $=$ & Red o \\
\hline & CRPXCrPX & $=$ & Red $q$ \\
\hline & CRPXerPX & $=$ & Red $O$ \\
\hline & CRPXoRPX & $=$ & Red $q$ \\
\hline & CRPXCRPX & $=$ & Red ? \\
\hline \multirow[t]{8}{*}{$\mathrm{F}_{2}$} & cRCrPX & $=$ & Red 0 \\
\hline & cRerPX & $=$ & White of \\
\hline & cReRPX & $=$ & White 0 \\
\hline & cRCRPX & $=$ & Red o \\
\hline & crCrPX & $=$ & Pink ${ }^{\pi}$ \\
\hline & ererPX & $=$ & White ot \\
\hline & crcRPX & $=$ & White ot \\
\hline & crCRPX & $=$ & Red of \\
\hline
\end{tabular}

The expectation is six red females to two pink females or 3 to 1 . The realization is close to expectation, there being a small deficit in pink females. For the males the expectation is three reds to one pink. The realization is 4 to 1 due to deficit in pink males. The expectation for white males is the sum of the pink and red males: the realization is not far from this number. The white males should be to the red males as $4: 3$ which is approximately realized.

The reciprocal cross, white-eyed females to pink-eyed males, gives in the first generation red-eyed females and white-eyed males. These inbred gave the following colors and ratios: 
Red-eyed

Red-eyed

White-eyed

White-eyed

Pink-eyed

Pink-eyed

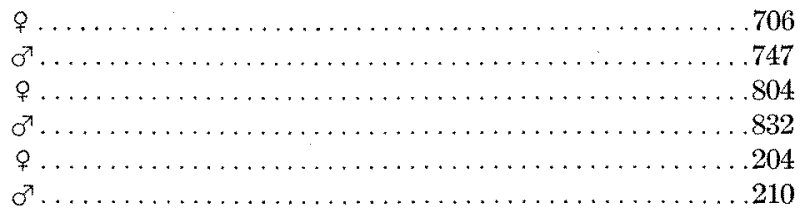

The application of the same formulae to this case gives the following results:

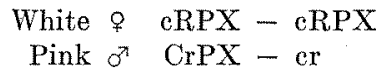

$\mathrm{F}_{1}$

Red $\%$ cRPXCrPX

White or cRPXer

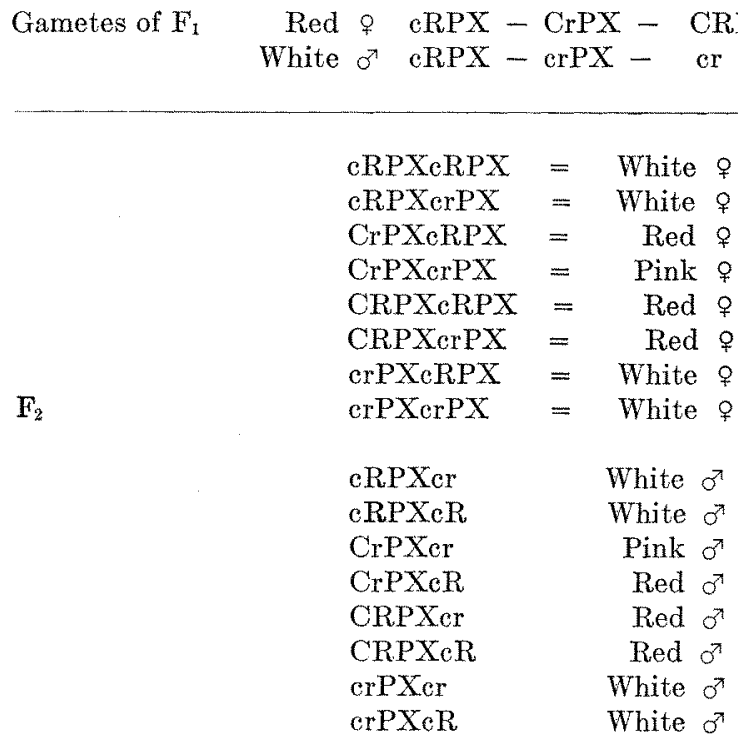

In both males and females the color ratio is 4 white, 3 red, 1 pink. The actual numbers are a fair approximation to this expectation. 


\section{HEREDITY OF TWO SEX-LIMITED CHARACTERS COMBINED WITH FOUR EYE COLOR CHARACTERS. ${ }^{3}$}

In this experiment a male with short proportionate wings and white eyes-both sex-limited characters-was mated to an orangeeyed female with long wings. The white-eyed male was a white from red stock, cRPO.

In the first generation all of the offspring had long wings like the mother's; the females had red eyes and the males had vermilion eyes. These were inbred and produced the second or $\mathrm{F}_{2}$ generation that contained flies having red, vermilion, pink, orange, and white eyes. In each of these classes, however, the short-winged individuals were males, as shown in the next table:

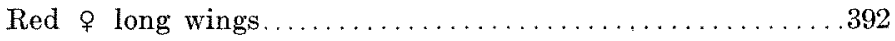

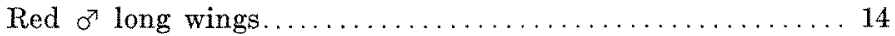

Red $\sigma^{t}$ short wings............................ 66

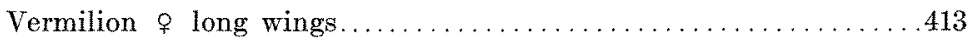

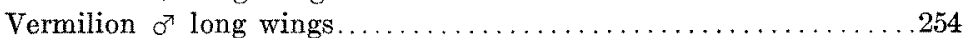

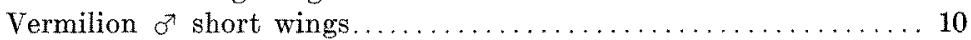

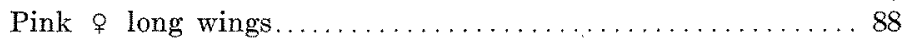

Pink or long wings $\ldots \ldots \ldots \ldots \ldots \ldots \ldots \ldots \ldots \ldots \ldots \ldots \ldots$

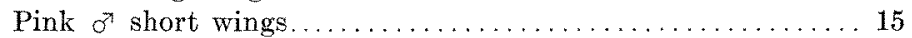

Orange o long wings . . . . . . . . . . . . . . . . . . . . . . 119

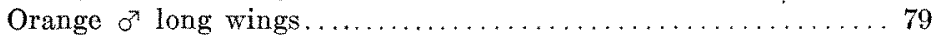

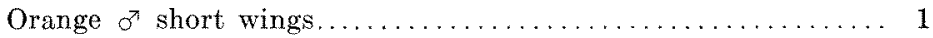

White $o^{x}$ long wings............................... 95

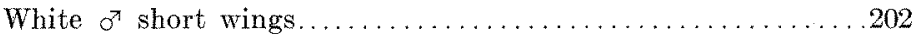

It will be observed at once that the inheritance of short wings and of white eyes is strictly sex limited. It will also be observed that each eye color has been combined with short wings, but only of course in the male sex. The total number of short winged males having red, vermilion, pink, and orange eyes is 92 , while

3 See also "The Method of Inheritance of Two Sex-Limited Characters in the Same Animal." Proc. Soc. Exp. Biol. and Med. vol. 8, Oct. 1910. 
the number of short winged males with white eyes is twice this number. In this connection I wish to point out that the grandfather had white eyes. The possible significance of this may be discussed later. It is obvious, however, on any theory of chance elimination of unit characters in the egg that the total number of males of all eye colors having short wings must be equal to the number of short winged white eyed males.

The analysis of the results following the same methods asheretofore is as follows:

Long-winged, orange-eyed o LCrpOX - LCrpOX

Short-winged, white-eyed or lcRPOXlcRpO

Long-winged, red-eyed $\subsetneq$ LCrpOXIcRPOX

Long-winged, vermilion-eyed $\sigma^{\rightarrow}$ LCrpOXlcRpO

$\mathbf{F}_{1}$

Gametes of $F_{1}$

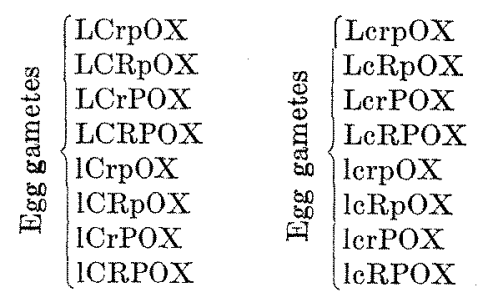

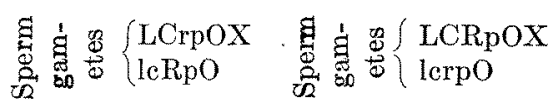

The random fertilization of these sixteen kinds of eggs by the two kinds of female-producing spermatozoa LCrpOX and LCRpOX and their fertilization by the two kinds of male producing spermatozoa lcRpO and lerpO is represented in the following table: 


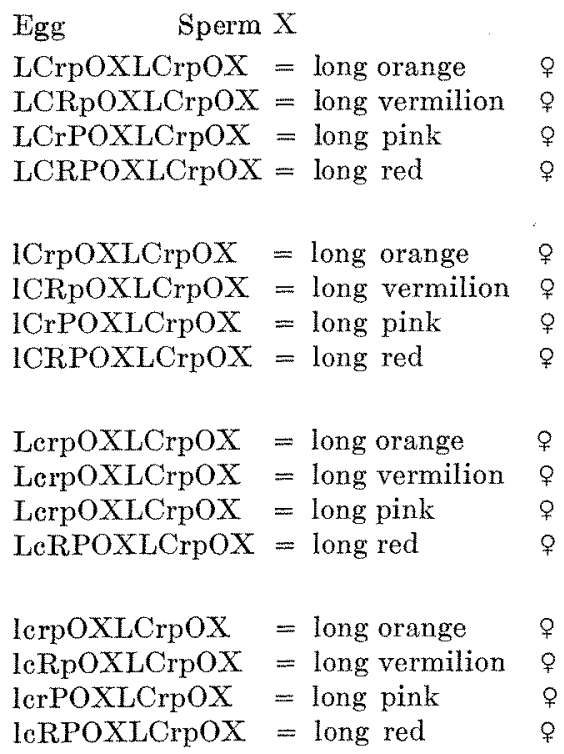

Egg Sperm no $\mathrm{X}$

\begin{tabular}{|c|c|}
\hline LCrp & $=$ long orange \\
\hline LCRpOXICrpO & $=$ long vermilion \\
\hline LCrPOXICrPO & $=$ long pink \\
\hline LCRPOXICrpO & $=$ long red \\
\hline $\mathrm{Crp}$ & $=$ short orange \\
\hline 1Crpo & $=$ short vermilion \\
\hline lCrPOXlCrpO & $=$ short pink \\
\hline 1CRPOX1CrpO & $=$ short red \\
\hline LerpOXICrpO & $=10 \mathrm{n}$ \\
\hline LeRpOXICrpO & $=$ long vermilion \\
\hline LerPOX1CrpO & $=$ long pink \\
\hline LcRPOXICrpO & $=$ long red \\
\hline ICrpOXICrp & $=s$ \\
\hline lCRpOXICrpO & $=$ shor \\
\hline $1 \mathrm{CrPOXICr}$ & $=$ short pink \\
\hline ICRPO & $=$ short red \\
\hline
\end{tabular}

Sperm X

LCRPOX $=$ long vermilion $\circ$ LCRpOX = long red $\quad$ क LCRpOX = long red $\quad$ क LCRpOX $=$ long vermilion of LCRpOX $=$ long red $\quad$ \% LCRPOX $=$ long red $q$

$\mathrm{LCRpOX}=$ Iong vermilion $q$ and $L C R p O X=$ long vermilion $o$ LCRpOX $=$ long red $\quad$ 우 LCRpOX $=$ long red o

LCRpOX $=$ long vermilion LCRpOX $=$ long red $\%$ LCRpOX = long red $\quad$ \% and $\begin{array}{lll}\text { leRpO } & =\text { long vermilion } & \sigma^{7} \\ \text { leRpO } & =\text { long vermilion } \sigma^{7}\end{array}$ $\mathrm{leRpO}=$ long red $\sigma^{7}$ $1 \mathrm{cRpO}=$ long red $\mathrm{o}^{x}$

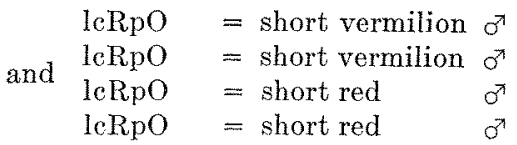

$\begin{array}{rll}\text { lcRpO } & =\text { long white } & \sigma^{7} \\ \text { and } \mathrm{lcRpO} & =\text { long white } & \sigma^{7} \\ \text { lcRpO } & =\text { long white } & \sigma^{7} \\ \text { lcRpO } & =\text { long white } & \sigma^{7}\end{array}$

lcRpO = short white or and leRpO = short white $0^{7}$ leRpO = short white $0^{7}$ leRpO = short white $0^{7}$ 
Summarizing this last table we get:

Long winged red $\% \ldots 12$

Long winged vermilion $q \ldots 12$ and

Long winged pink $\& \ldots 4$

Long winged orange $9 . .4$
Long winged red $0^{7} \ldots .4$

Long winged vermilion $\sigma^{7} \ldots . .4$

Long winged pink or .... 2

Long winged orange $\sigma^{7} \ldots 2$

Long winged white 0 ....4 4

Short winged red $0^{7} \ldots . .4$

Short winged vermilion o ${ }^{7} \ldots . .4$

Short winged pink $\sigma^{7} \ldots 2$

Short winged orange $\sigma^{7} \ldots \ldots 2$

Short winged white $\sigma^{7} \ldots \ldots 4$

There should be, obviously, as many females as males. The results show 1012 females and 743 males. There is a distinct falling off of males. The two sexes give about 10 to 8 or 5 to 3 .

In each class with eye color the males should be the same in number in the red and the vermilion; and in the pink and the orange. A great variability is however realized as shown below:

\begin{tabular}{l|r|r|r|r|r} 
& RED & vERMLIION & PINK & ORANGE & WHITE \\
\hline Long winged $\sigma^{7} \ldots \ldots \ldots \ldots \ldots \ldots$ & 14 & 254 & 7 & 79 & 95 \\
Short winged $\sigma^{7} \ldots \ldots \ldots \ldots \ldots \ldots$ & 66 & 10 & 15 & 1 & 202 \\
\hline
\end{tabular}

The enormous discrepancy between theory and fact shown by the table may well make one reject the theory as totally inadequate to explain the facts. Nor can one appeal to the relative viability of the males to help him out of the dilemma; for, the long winged normal males run far behind the number for the vermition, orange, and white; yet the long winged red eyed males are normal for the species, and do not run behind under the same conditions used in this experiment. A closer scrutiny of the table will, however, indicate a relation that may be very significant. The great excess of males is found in two classes, the long winged vermilion and the short winged white male, and these are respectively the father (the same as the grandmother's combination) and the grandfather of this $F_{2}$ generation! 


\section{THE INHERITANCE OF THREE SEX-LIMITED CHARACTERS}

In the following four crosses three sex-limited characters are involved: white eyes, short wings; and yellow color. In the first two crosses all these characters are contained in one of the parents; in the other two crosses two of the characters are in one parent and one in the other.

In earlier papers (Science, 1910 and 1911) I have described the main facts for inheritance of red versus white eyes, and long versus short (short proportionate) wings. In order to understand the relation of yellow to normal color, the following experiment may be cited. A long, red, normal (body color) female was crossed with a long, red, yellow male. The offspring, both male (654) and female (705), were long, red, normal. These inbred gave:

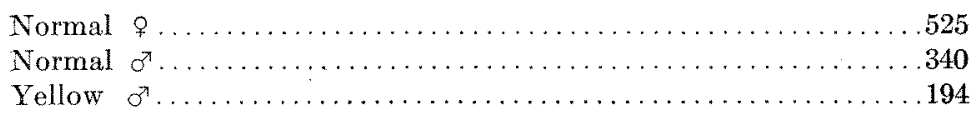

The reciprocal cross, viz., long, red, yellow female by long, red, normal male, gave females (397) with long wings, red eyes, normal color and males (282) with long wings, red eyes, and yellow color. These inbred gave:

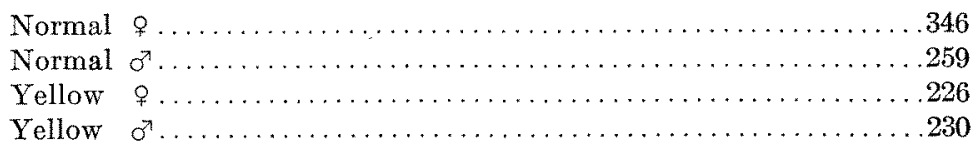

We are now in position to take up the experiments in which three sex-limited characters, white eyes, short wings, and yellow color are involved; see Plate I.

When a yellow, short winged, white eyed male is bred to a normal wild fly with normal color, long wings, and red eyes, all the offspring are like the mother, i.e., normal color, long wings, red eyes. 
YWS $\sigma^{7}$ by NRL $q=\left\{\begin{array}{l}\text { NRL } q=\text { Normal red long } q \\ \text { NRL } \sigma^{7}=\text { Normal red long } \sigma^{7}\end{array}\right.$

These inbred have produced four main classes of males, and three small classes, represented by a few male flies only; the females are represented by but a single class, as shown below:

Normal Color

\begin{tabular}{|c|c|c|c|c|c|c|c|}
\hline \multicolumn{4}{|c|}{ RED EXES } & \multicolumn{4}{|c|}{ WHTE EXES } \\
\hline \multicolumn{2}{|c|}{ Long wings } & \multicolumn{2}{|c|}{ Short wings } & \multicolumn{2}{|c|}{ Long wings } & \multicolumn{2}{|c|}{ Short wings } \\
\hline $\begin{array}{c}q \\
1879\end{array}$ & $\begin{array}{c}\sigma^{7} \\
606\end{array}$ & $q$ & $\begin{array}{c}0^{7} \\
167\end{array}$ & 우 & $\begin{array}{l}7 \\
1\end{array}$ & $q$ & $\begin{array}{l}0 \\
3\end{array}$ \\
\hline
\end{tabular}

Yellow Color

\begin{tabular}{|c|c|c|c|c|c|c|c|}
\hline \multicolumn{4}{|c|}{ RED EYBS } & \multicolumn{4}{|c|}{ WHITE EYES } \\
\hline \multicolumn{2}{|c|}{ Long wings } & \multicolumn{2}{|c|}{ Short wings } & \multicolumn{2}{|c|}{ Long wings } & \multicolumn{2}{|c|}{ Short wings } \\
\hline$q$ & $\begin{array}{l}0^{7} \\
7\end{array}$ & $q$ & $0^{x}$ & 우 & $\begin{array}{c}0 \\
143\end{array}$ & $q$ & $\begin{array}{l}7 \\
96\end{array}$ \\
\hline
\end{tabular}

In addition to the flies recorded in the table there were two females belonging to two classes, viz., one, normal, long, white female; and one, yellow, long, white female. I shall not hesitate to ignore these two cases as exceptional, due either to accidental contamination through the food, or to sporting within the stock. Omitting these two females it will be seen that all of the females fall into one class having normal color, long wings, and red eyes. In all there were 1879 of these females, as against 1022 males. The females are, therefore, almost twice as numerous as the males. The three sex-limited characters appear only in the grandsons; one class containing all three sex-limited characters, yellow, short, white (96); one class containing two sex-limited characters, yellow, white (143); and one class containing one sex-limited character, short wings (167). For the moment the other three classes of males may be left out of account. It will be noticed also that the grandfather's combination is well represented by 96 
individuals, while the father's combination which is the grandmother's also is represented by the great majority of all the males (606). The remaining large class contains two of the grandfather's characters, viz., yellow and short. Of the three small classes of males, one contains two of the grandfather's characters, viz., white and short, and one contains one of his characters, viz., yellow color.

In my first attempt to analyze this case I ignored the three small classes of males because I found empirically that the remaining classes and the females could be very simply accounted for, as the following formulæ will show.

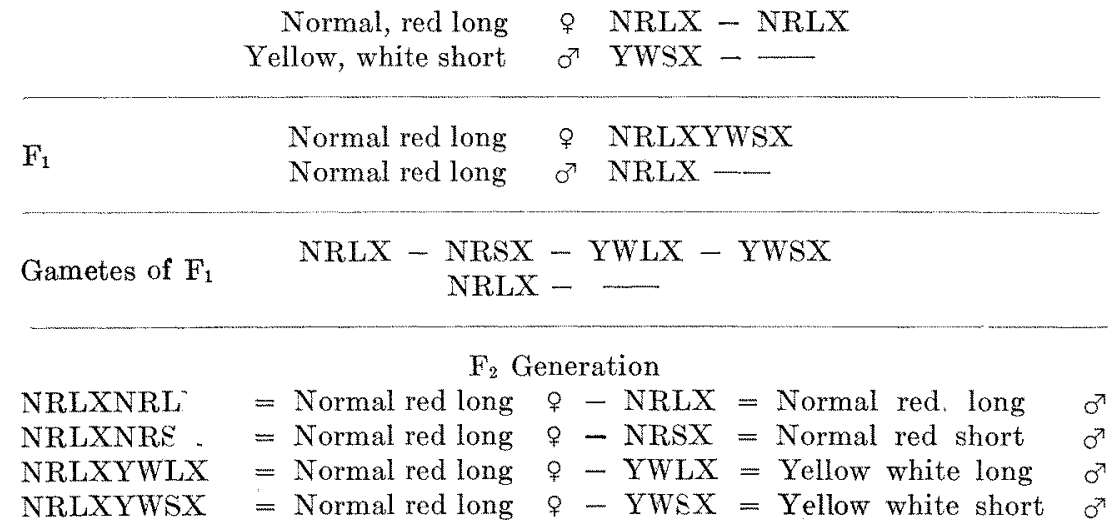

This scheme meets with two serious difficulties. It calls for equal numbers of each kind of male while in reality one class is at least three times as numerous as any one of the others. If we tried to explain this anomaly (as in fact I think we must) on the basis of some sort of "association" taking place, we still have to meet a more serious theoretical difficulty. It will be seen that only four classes of eggs are represented in the $\mathrm{F}_{1}$ generation. There are two classes of eggs containing $\mathrm{N}$ and $\mathrm{R}$, and two containing $\mathrm{Y}$ and $\mathrm{W}$, but no class containing $\mathrm{N}$ and $\mathrm{W}$, and none containing $\mathrm{Y}$ and $\mathrm{R}$. No theoretical explanation can admit this arbitrary treatment, for the theory on which we are working demands the full interchange of all of these charactersunless some special reason can be given for failing in this regard. 
Now it will be seen that the combinations of $N$ and $R$, and $Y$ and $\mathrm{W}$ are the combinations that existed in the parents of this cross. To admit the foregoing scheme requires the recognition of this union as permanent in subsequent generations. Yet this is opposed to the Mendelian treatment of the case, unless association is admitted as valid.

If now we take up the case of the three small classes of males we find no place for them in this scheme. I see no reason for ignoring them, small though the classes be. This consideration leads me to the conclusion that instead of four classes of eggs in the $F_{2}$ generation, the possibility of eight classes must be admitted, but owing to the initial association of $\mathrm{N}$ and $\mathrm{R}$, and $\mathrm{Y}$ and $W$, their separation only occasionally occurs. When it does, the small classes of males appear, and the number of individuals in these classes is a measure of the infrequency with which the separation occurs. The scheme when fully worked out is as follows:

$$
\begin{aligned}
& \text { Normal female NRLX - NRLX } \\
& \text { yellow white short of YWSX - }
\end{aligned}
$$

$F_{1} \quad$ Normal o NRLXYWSX

Normal or NRLX -

$$
\begin{gathered}
\text { Gametes of } F_{1} \\
\text { NRLX - NRSX - NWLX }- \text { NWSX }- \text { YWSX }- \text { YWLX }- \text { YRSX }- \text { YRLX } \\
\text { NRLX - }
\end{gathered}
$$

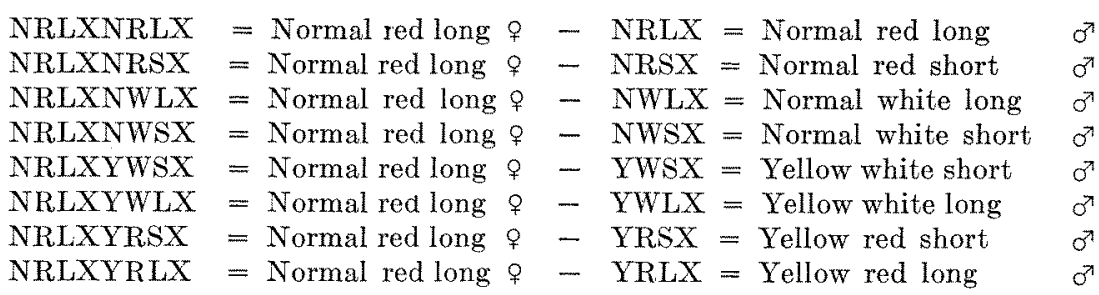

It is seen that the two factors $\mathrm{N}$ and $\mathrm{W}$ (or Re) tend to hold together. Both are contained in the sex chromosome, i.e., $\mathrm{N}$ and c are there. Both are present in the grandmother, and through 
her carried into her son-the father of the $F_{2}$ generation. The grandmother transmits only one $\mathrm{X}$ to her grandson-the one in question. It is also seen that the two factors $\mathrm{Y}$ and $\mathrm{R}$ tend to hold together in the same way. On the other hand the factor for long and short wings seems freer to leave one $\mathrm{X}$ and pass to its partner without showing any very great tendency to associate with the color factors in X.

The reciprocal cross, viz., a female with yellow color, white eyes, and short wings, bred to a normal male with normal color, red eyes, and long wings, gave females with normal color, red eyes, and long wings, and males with yellow color, white eyes, and short wings.

YWS $q$ by NRL $\sigma=\left\{\begin{array}{l}\text { NRL } q=\text { normal red long } q \\ \text { YWS } \sigma^{\pi}=\text { yellow white short } \sigma\end{array}\right.$

These inbred gave the classes in the next tables:

Normal Color

\begin{tabular}{|c|c|c|c|c|c|c|c|}
\hline \multicolumn{4}{|c|}{ RED EYES } & \multicolumn{4}{|c|}{ WHITE EYES } \\
\hline \multicolumn{2}{|c|}{ Long wings } & \multicolumn{2}{|c|}{ Short wings } & \multicolumn{2}{|c|}{ Long wings } & \multicolumn{2}{|c|}{ Short wings } \\
\hline $\begin{array}{c}\stackrel{9}{4} \\
439\end{array}$ & $\begin{array}{c}0^{7} \\
319\end{array}$ & $\begin{array}{c}9 \\
208\end{array}$ & $\begin{array}{c}0^{7} \\
193\end{array}$ & $\begin{array}{l}q \\
1\end{array}$ & $\sigma^{7}$ & $\begin{array}{l}\text { 우 } \\
5\end{array}$ & $\begin{array}{c}\text { o } \\
11\end{array}$ \\
\hline
\end{tabular}

Yellow Color

\begin{tabular}{|c|c|c|c|c|c|c|c|}
\hline \multicolumn{4}{|c|}{ RED EYYES } & \multicolumn{4}{|c|}{ WHITE EYES } \\
\hline \multicolumn{2}{|c|}{ Long wings } & \multicolumn{2}{|c|}{ Short wings } & \multicolumn{2}{|c|}{ Long wings } & \multicolumn{2}{|c|}{ Short wings } \\
\hline $\begin{array}{l}q \\
7\end{array}$ & $\begin{array}{l}\sigma^{7} \\
5\end{array}$ & 우 & $\sigma^{7}$ & $\begin{array}{r}\text { ㅇ } \\
178\end{array}$ & $\begin{array}{r}\sigma^{7} \\
139\end{array}$ & $\begin{array}{c}\text { } \\
365\end{array}$ & $\begin{array}{r}\text { 7 } \\
335\end{array}$ \\
\hline
\end{tabular}

Here again the two pairs of grandparental characters, viz., normal color with red eyes; and yellow with white eyes, are represented by the eight large classes in the $\mathrm{F}_{2}$ generation; while short and long wings are nearly equally distributed. But even here there are more grandchildren with normal color, red eyes, and 
long wings, than with short wings. These two colors went together with long wings in the grandfather. Conversely; the grandmother combined short wings with yellow color and white eyes, and there is an excess of short winged grandchildren ( $\sigma^{7}$ and $q$ ) over long winged ( $\sigma^{7}$ and $q$ ). The shorter analysis is as follows:

Yellow, white, short \& YWSX - YWSX

Normal, red, long or NRLX - -

$\mathrm{F}_{1}$

Normal $\&$ YWSXNRLX

Yellow, white, short ox YWSX

Gametes of $F_{1} \quad$ YWSX - YWLX - NRLX - NRSX

YWSXYWSX $=$ Yellow white short $\circ-$ YWSX Yellow white short $\sigma^{7}$ YWSXYWLX $=$ Yellow white long $q$ - YWLX Yellow whitelong or YWSXNRLX $=$ Normal red long $q-$ NRLX Normal red long $\sigma^{7}$ YWSXNRSX $=$ Normal red short $q$ - NRSX Normal red short $\sigma^{2}$

If the more extended analysis for the gametes of the female were used there would be four more classes of eggs, namely, YRSX, YRLX, NWLX, NWSX, which would give four new classes of females, namely, yellow, red, short; yellow, red, long; normal, white, long; and normal, white, short; of which the second, third, and fourth are represented in the table by seven, one and four females respectively. The extended analysis would also give four other classes of males, whose formulae correspond to those of the four new types of eggs given above in the text, of which two are realized and two are not.

In the third cross, a female with normal color, white eyes, and short wings was bred to a male with yellow color, red eyes, and long wings. The female offspring had normal color, red eyes, and long wings, and the male offspring had normal color, white eyes, and short wings.

NWS $\&$ by YRL $\sigma^{7}=\left\{\begin{array}{l}\text { NRL } q=\text { Normal red long } \% \\ \text { NWS } n^{7}=\text { Normal white short } n^{7}\end{array}\right.$ 
The $\mathrm{F}_{1}$ 's inbred gave the classes shown in the next table:

Normal Color

\begin{tabular}{|c|c|c|c|c|c|c|c|}
\hline \multicolumn{4}{|c|}{ RED EYES } & \multicolumn{4}{|c|}{ WHITE EXES } \\
\hline \multicolumn{2}{|c|}{ Long wings } & \multicolumn{2}{|c|}{ Short wings } & \multicolumn{2}{|c|}{ Long wings } & \multicolumn{2}{|c|}{ Short wings } \\
\hline q & $\sigma^{7}$ & q & $0^{x}$ & q & $0^{7}$ & q & $\sigma^{7}$ \\
\hline 439 & 7 & 235 & & 218 & 237 & 359 & 387 \\
\hline
\end{tabular}

Yellow Color

\begin{tabular}{|c|c|c|c|c|c|c|c|}
\hline \multicolumn{4}{|c|}{ RED EYES } & \multicolumn{4}{|c|}{ WHITE EY } \\
\hline \multicolumn{2}{|c|}{ Long wings } & \multicolumn{2}{|c|}{ Short wings } & \multicolumn{2}{|c|}{ Long wings } & \multicolumn{2}{|c|}{ Short wings } \\
\hline 우 & $\begin{array}{c}0^{7} \\
345\end{array}$ & q & $\begin{array}{c}\sigma^{7} \\
210\end{array}$ & 우 & $\sigma^{x}$ & q & $\begin{array}{l}0 \\
4\end{array}$ \\
\hline
\end{tabular}

In the second generation there are four kinds of females and six kinds of males. If we recognize the union of $N$ and $W$ and $Y$ and $R$ in the gametes of $F_{1}$ (the union that was present in the grandparents) the expectation on the shorter analysis is as follows:

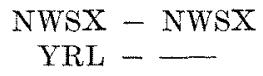

$\mathrm{F}_{1}$

Normal, red long o NWSXYRLX

Normal, white short on NWSX -

Gametes of $F_{1} \quad$ NWLX - NWSX - YRLX - YRSX

NWSXNWLX $=$ Normal, white long $\%-$ NWLX $=$ Normal white long $\sigma^{\circ}$ NWSXNWSX $=$ Normal, white short $\wp-$ NWSX $=$ Normal white short $\sigma^{\prime}$ NWSXYRLX $=$ Normal red long $\quad$ - YRLX $=$ Yellow, red, long $\sigma^{7}$ NWSXYRSX $=$ Normal, red short $q-$ YRSX $=$ Yellow, red short

If we admit the more extended segregation, the same disproportions appear, but the two smaller classes of males are now represented and two classes of males do not appear at all (as in the 
realization). In regard to the couplings in these cases it is of great importance to notice that once more the long and short factors segregate without regard to the color factors, yet even here a remarkable fact comes to light. The two classes of males that exceed the others are those in which the long, red, yellow combination and the short, white, normal combination exist. These are the two combinations that were in the grandparents. If we assume that they more often remain in the same chromosome the numerical results become apparent.

In the fourth cross, a male with normal color, white eyes, and short wings was bred to a female with yellow color, red eyes, and long wings. The female offspring had normal color, red eyes, and long wings, and the males had yellow color, red eyes, and long wings.

$$
\text { NWS } \sigma^{7} \text { by YRL } q=\left\{\begin{array}{l}
\text { NRL } q=\text { Normal red long } \\
\text { YRL } \sigma^{7}=\text { Yellow red long }
\end{array}\right.
$$

The second or $\mathrm{F}_{2}$ generation is represented in the next table:

\begin{tabular}{|c|c|c|c|c|c|c|c|}
\hline \multicolumn{4}{|c|}{ FED EYES } & \multicolumn{4}{|c|}{ WHITE EYCS } \\
\hline \multicolumn{2}{|c|}{ Long wings } & \multicolumn{2}{|c|}{ Short wings } & \multicolumn{2}{|c|}{ Long wings } & \multicolumn{2}{|c|}{ Short wings } \\
\hline $\begin{array}{c}\text { } \\
608\end{array}$ & $\begin{array}{l}0^{7} \\
2\end{array}$ & $q$ & a & \% & $\begin{array}{r}0^{7} \\
137\end{array}$ & q & $\begin{array}{r}\text { の } \\
237\end{array}$ \\
\hline
\end{tabular}

\begin{tabular}{|c|c|c|c|c|c|c|c|}
\hline \multicolumn{4}{|c|}{ RED EYES } & \multicolumn{4}{|c|}{ WHITE EYES } \\
\hline \multicolumn{2}{|c|}{ Long wings } & \multicolumn{2}{|c|}{ Short wings } & \multicolumn{2}{|c|}{ Long wings } & \multicolumn{2}{|c|}{ Short wings } \\
\hline $\begin{array}{c}q \\
389\end{array}$ & $\begin{array}{r}0 \\
248\end{array}$ & q & $\begin{array}{c}8^{3} \\
101\end{array}$ & q & $\begin{array}{l}0^{7} \\
1\end{array}$ & $q$ & $\begin{array}{l}0^{7} \\
1\end{array}$ \\
\hline
\end{tabular}

Only four large classes of males are represented and it is significant that these are the yellow-red and the normal-white-the two combinations that correspond to the two grandparental com- 
binations. These two classes occur both in the long and short wings, but here again occurs the significant fact that the yellow, red, long are twice as frequent as the yellow, red, short. The former is the grandmaternal combination. Again the normal, white, short are nearly twice as numerous as the normal, white, long and it is the former combination that is characteristic of the grandfather. The shorter analysis follows:

YRLX-YRLX

NWSX - -

F $\quad$ Normal red long o YRLXNWSX

Yellow red long ơ YRLX -

Gametes of $F_{1} \quad$ YRLX $-\underset{\text { YRLX }}{\text { YRLX }}-$ NWLX - NWSX

YRLXYRLX $=$ Yellow, red, long $\subsetneq-$ YRLX $=$ Yellow, red, long $\sigma^{7}$

YRLXYRSX = Yellow, red, long o - YRSX = Yellow, red, short or

YRLXNWLX = Normal red, long $q-$ NWLX $=$ Normal, red, long $\sigma^{7}$

YRLXNWSX $=$ Normal red, long of - NWSX $=$ Normal, red, short $0^{x}$

The same objections may be urged against this scheme that have been given for the first short scheme. It is unnecessary to write out the longer scheme again in this case as the same principle employed in the first instance is applicable here. Of the four additional classes of males called for by the longer analysis, three appear in the results represented by any 2,1 , and 1 males respectively. 
PART V

\section{CONCLUSIONS}

\section{A THEORY TO ACCOUNT FOR "ASSOCIATIVE" INHERITANCE}

In the preceding pages I have tried to show how the mechanism that exists in the chromosomes can be applied to the mechanism of heredity, provided we deal with particles or chemical substances in the chromosomes rather than with the chromosomes as units. The evidence makes out, I believe, a very strong case in favor of the idea that sex-limited inheritance is connected with the same physical body that determines sex, and I have not hesitated to identify that body with the sex chromosome. The second point of significance in the results is that while in the female there may be an interchange between homologous chromosomes, no interchange takes place in the male of those factors connected with sex-limited inheritance. We can explain this result if these characters are contained in the single $\mathrm{X}$ chromosome in the male which alone has no mate. The third point of interest in these results is the necessity of assuming some combination or rather localization amongst some of the substances resident in the same chromosome. The peculiar ratios found in the second generation find their explanation only by means of such an assumption. Couplings and linkages have been described before to account for observed ratios, notably by Bateson and his collaborators, but I think we see here clearly for the first time that these unions are not due to inherent relations, or fusions, or attractions, or correlations, or repulsions, but to juxtaposition of particles in the chromosomes. It has been shown in a considerable number of cases that at one stage in the process of union of homologous chromosomes the members of each pair twist around each other like the components of a rope. Subsequently these twisted chromosomes fuse together and shorten. Later a longitudinal split appears in the shortened, double chromosome. This split now lies in one plane, i.e., it does not follow the turns of the united chromosomes. In consequence of the position of the new plane 
of splitting or division each half, or new chromosome, must be made up of parts of one and parts of the other of the two original chromosomes that united in pairs as Janssens has shown. As a result of the subsequent "reduction" division the cells that are produced will contain new combinations of the materials composing the original chromosomes. If the chromosomal materials that represent the factors of heredity are placed lineally along the chromosome and in corresponding linear series in each pair of homologous chromosomes, random separation of these materials will be brought about by means of the cell mechanism, explained above, except in those cases where the materials lie near together. In the former case, the usual Mendelian random segregation will take place; in the latter case, groups of factors will tend to remain together or be associated in heredity. These latter cases correspond to those in which we find "association" to occur. It will be observed that while such associations will be more or less common according to the nearness of the associating factors in the chromosome, the associations are not absolute for occasionally the twisting of the chromosomes will be such that even regions lying lineally near together will come to lie on opposite sides of the united chromosomes. These cases represent the small classes observed in the tables. In the case of the $\mathrm{X}$-chromosomes we should expect interchanges of the postulated kind to occur when two X's are present, as in the female of Drosophila; but no interchanges when only one $\mathrm{X}$ is present as in the male. The experimental results accord completely with this anticipation and afford strong evidence in favor of the view expressed above. This assumption seems to be far simpler than the assumption of attractions, repulsions and complicated ratios that Bateson has suggested as an interpretation of similar phenomena.

It is obviously not essential to this hypothesis of factoral interchange to limit it to the particular stage of the chiasma type here suggested, for if a similar phenomenon occurs at any other stage in division the same results will follow. 
DISINTEGRATION OF A SPECIES AND ITS RECONSTITUTION BY RECOMBINATION

The series of mutations that have appeared in Drosophila can all be accounted for on the assumption of losses from the original germ-plasm. There is possibly one exception to this rule, namely, the melanitic or black mutant that may appear to add something to the original color. When crossed to the normal it gives an intermediate type in the first generation, and this fact also might be urged in favor of the change being in a positive direction. But since in the second generation the black fly appears as the recessive type it is not improbable that even this mutant may be due to loss. The most convincing proof that the eye and wing mutations are due to loss is found in the reconstitution of the original or wild type when certain recombinations are made. So many examples of this have been given in the preceding pages that I need not go over the evidence again. Two points, however, may be recalled as instructive. In several combinations the female alone is reconstituted. In the older terminology the female is the atavist, the male is the neomorph; and it is always the female and never the male that shows this relation if either one is atavistic. The reason for this is also clear from the evidence-the male-producing sperm has all the recessive factors in question, while the female-producing sperm has one or more dominant factors. No better example than this one of unisexual atavism, or reconstitution, could be cited to show the advantage that the modern explanation of heredity has over the older view, where a fact of this kind would have seemed totally inexplicable.

The second point of interest in this evidence is found in the different behavior in heredity of the original and of the reconstituted (atavistic) type, for while the wild type continues to breed true the reconstituted type splits later into its components. The reconstituted type may be said to be physiologically complete, but morphologically dismembered. For example, when a vermilion male is bred to a pink female, all of the offspring are red. The four substances, R P O C, necessary to produce red have 
been brought together, so that all the elements of the wild fly are present that collectively give red eye-color; but now instead of the chromosomes that carry these substances being represented in duplicate, some of the chromosomes lack one or the other substance. It is due to this that the splitting takes place in the formation of the germ-cell of these reconstituted types. Nevertheless it is possible even to reconstruct the original wild forms by suitable combinations, such, for example, as will give in duplex the four factors essential to the development of red eyes, and the structurally reconstituted types will breed as true to type as the wild flies, in contrast to the atavists that are only physiologically reconstituted.

THE PRESENCE AND ABSENCE THEORY IN RELATION TO THE THEORY OF ASSOCIATION

The appearance of so many mutants, due to losses, raises the question as to whether all new types that follow Mendel's law may come under the same category. There are types, it is true, among domesticated forms that appear to have added something to the original type from which the mutants arose, but some of these are due to hybridization, and some may be due to losses of inhibiting factors, whose absence permits the further elaboration of characters already present. As yet the evidence is insufficient, I think, to allow any certain generalization in this regard, yet the evidence suffices at least to show that many or even most cases that follow Mendel's law fall under this head. In so far as the mutants are due to losses they are explicable on the presence and absence theory, which may seem to give some grounds for the universal application of this principle. There is, however, one possibility that we can not afford at present to ignore, namely, the evidence of "association" which is clearly furnished by some of the crosses described in the preceding pages. I should like to dwell a little further on this point. If I am right in explaining the results of those cases where two or three sex-limited characters are involved on the grounds of the juxtaposition of substances (factors) in the chromosomes, it is only a step further to cases, 
like those of the gray mouse when the color factors for gray, namely, black, yellow, chocolate, and ticking, remain permanently associated when crossed with a mutant which contains only one of these same factors. Thus when a yellow bearing germ cell meets one bearing gray, all of the offspring are yellow. These yellows inbred produce only grays and yellows and not blacks and chocolates also, as should happen, did each of the elements in the original gray have for its mate the absence of its particular factor. ${ }^{4}$ In Drosophila the eye color is made up of three or four color factors. When a wild female is crossed to one of the mutants an orange eyed male for example, all of the offspring are red. In the $\mathrm{F}_{2}$ generation not only red and orange, but pink and bright red also appear, although even here there is a stronger tendency for the original red to reappear more often than its products. It seems to me probable at least that the difference between the mice and the fly in this respect may be due to the closer association of the factors in the mice than in the fly. If so, the difference is one of degree only and not of kind.

\section{THE FERTILITY OF DEFICIENT MUTATIONS}

A striking fact in regard to most if not all of these mutations in Drosophila is their infertility compared with the original stock kept under identical conditions. As I have this matter under investigation I wish here to touch on it very briefly, and only in so far as it bears on the numerical proportions of the different types. The pure stock of several of the new types is less productive than the original stock, and the failure in several cases of the deficient types to appear in the expected ratios suggests that this failure is due in part to the failure in fertility or in vitality of the new types. Whether this is due to failure in the development of the egg, or of the sperm, or to failure to fertilize, or to lack of development of the embryo, are points requiring special study, but the facts are sufficiently numerous to raise the question as to whether a type that lacks some material present in the original

${ }^{4}$ See Morgan, T. H. The influence of the environment and of heredity on the inheritance of coat color in mice. New York Academy of Science. 1911. 
stock may not in many cases lose also its full power of productivity. It may seem improbable that the presence of some substance necessary for the development of a particular color in the eye could have any influence on the rest of the germ, but the same substance that is essential for eye color may be essential for the production of other things in the body that are not so apparent. In fact, I have already obtained evidence in the case of the eye color-producer, $\mathrm{C}$, that the absence of $\mathrm{C}$ not only affects the eyecolor, but other parts in the body as well. It is not impossible, therefore, that in certain cases the absence of a factor may have an important influence in one or another way on the productivity of the animal. I do not wish to discuss further this question until I can bring forward certain evidence that bears directly on it, but I have raised the question here, first in order to point out its possible bearing on the disturbance of Mendelian ratios, and second, in order to make clear that while I regard the evidence in favor of the mosaic inheritance of certain characters as established, I am not unappreciative of the fact that a simple factor may have a wider influence in development than appears when only a single character is under consideration.

\section{ORIGIN OF MUTATIONS THROUGH CHROMATIN LOSSES}

The mutations that have occurred in Drosophila may throw some light on the origin of mutations in general. If my analysis is correct it follows that mutations arise not through losses of whole chromosomes as some cytologists have hinted (for the individual chromosomes must be supposed to carry not one but a host of factors) nor through the doubling of one or of all of the chromosomes (which would only add to what is already present in duplex) but mutations arise through the regrouping of particular substances carried by the chromosomes. These substances may be so small in amount that their absence may entirely escape a cytological examination. It would seem that ample opportunity must be present for losses of this kind, since any irregularity in the division of the chromatin in the germ tract would lead to the appearance in time of a mutant if such were viable and if the 
right combinations were brought about. If, for instance, in the division of the spermatogonial cells the material particles at any level should fail to divide when the rest of the chromosome divides, one of the resulting cells will be deficient in the substance in question, and its offspring will be correspondingly deficient. Or if after synapsis similar particles in homologous chromosomes should pass into one chromosome, instead of segregating, one of the resulting cells will be deficient. The wonder is that such losses are so infrequent.

THE BEARING OF THE RESULTS ON THE CONSTITUTION OF THE SEX CHROMOSOMES

The experiments on Drosophila have shown that a most complicated series of facts relating to sex-limited inheritance can be accounted for, as I pointed out in my paper of 1910, on the assumption that one of the factors for such characters is combined with the sex factors, X, or more specifically (Morgan, ${ }^{5}$ Wilson 1911) if it is contained in the accessory or sex chromosome. The absence of this chromosome in half of the spermatozoa, and the impossibility of an interchange between this simple X-chromosome in the male (since $X$ has no pair in synapsis) is the significant feature of the explanation. What is most important, is the discovery that the $X$-chromosome contains not only one of the essential factors in sex determination, but also all other characters that are sex-limited in inheritance.

The discovery of this relation leads us a step farther, I think, in the analysis of the problem of sex determination, for it shows that the determination of sex is only one of several (perhaps of a large number of) properties contained in the sex chromosomes. Only by the loss of a factor from one of the other X's (in the female) is it possible to aiscover just how many factors are contained in X. Already four or five such losses have appeared in my mutations. This leads at once to the inference that it is not the $X$-chromosomes, as such, that is a factor in sex determination. but unly a very small part of its material.

${ }^{5}$ In a paper read before the American Society of Naturalists, December 29, 1910. Published in American Naturalist, 1911. 
I suggested in 1905 that the female sex is determined by the presence of more chromatin in the fertilized egg. Wilson suggested in 1906 that it is a particular chromosome that gives the quantitative results (or at least a more or less 'active' chromosome). The results of the experiments dealing with sex-limited inheritance in Drosophila demand that we go one step further, for they show that it is only a small part of this chromosome that is involved in sex determination.

If this is admitted we can understand how sex may be regulated in the same way, even when $\mathrm{X}$ and its mate $\mathrm{Y}$ appear to our relatively gross methods of measurement to be equal. The difference in size between $\mathrm{X}$ and $\mathrm{Y}$ that gives a completely graded series in different species has little to do, therefore, with conditions relating to sex determination, except in so far as the initial loss of the sex substance contained in $\mathrm{Y}$ led to a decrease in size. I am inclined to think that the difference in size relation between $\mathrm{X}$ and $\mathrm{Y}$ represents largely the loss from $\mathrm{Y}$ of those materials that play a rôle in sex-limited inheritance. If $X$ is the sex chromosome, then $Y$ is the sex-limited chromosome in a double sense. Its final disappearance in certain forms represents the total loss of all characters that can become sex-limited in inheritance.

If it is legitimate to draw any inference from the analogy between sex determining factors, and factors that determine other characters of the organism, it follows with a fair degree of plausibility that Y lost a sex factor (contained in the three X's of the species, 2 in the female, 1 in the male) in the same way that it has lost other factors also. If these factors are, as I have suggested, on a par, it follows that the material in question is the female determining factor, $\mathrm{F}$. Where then is the male determining factor? I have given my reason recently for dissenting from the position taken by several writers that the male condition is simply less $X$ chromatin. It seems to me that if we treat the problem of sex determination by the same methods used for Mendelian characters in general, we can not justify such a position but are led inevitably to the conclusion that if the X-chromosome contains (not is) the factor for producing a female, the factors 
for producing the male must be located in some other chromosome. ${ }^{6}$ This interpretation I have developed briefly in a recent article ${ }^{7}$ in which the female factor supposed to be contained in the $\mathrm{X}$ chromosome is represented by $\mathrm{F}$ and the male factor, supposed to be contained in some other chromosome (not in $\mathrm{Y}$ however which is ranked with the three X's except in so far as certain factors have been lost), is represented by M. The following scheme shows how the relation of the sexes on this basis and how sex is determined:

\begin{tabular}{rlll}
$\begin{array}{c}\text { Gametes of female FM-FM } \\
\text { Gametes of male FM-M }\end{array}$ & or & $\begin{array}{l}\text { XM-XM } \\
\text { XM-M }\end{array}$ \\
$\begin{aligned} \text { female FMFM } \\
\text { male FMM }\end{aligned}$ & or & $\begin{array}{l}\text { XMXM } \\
\text { XMM }\end{array}$ \\
\hline
\end{tabular}

\footnotetext{
${ }^{6}$ Not in $\mathrm{X}$ because in males having only one $\mathrm{X}$ (no $\mathrm{Y}$ ) the scheme will not work out.

${ }^{7}$ The application of the conception of pure lines to sex limited inheritance and to sexual dimorphism. The American Naturalist, Feb., 1911.
} 
PLATE 1

EXPLANATION OF FIGURES

1 Normal red-eyed fly.

2 Yellow fly with white eyes and "short proportionate" (or miniature) wings.

3 Short winged fly (as in fig. 2) with normal color and white eyes.

4 Brown fly with red eyes and long wings. This fly is yellowish, but differs from fig. 2 in the absence of a black factor (absent also in fig. 2) as well as a second factor probably a yellow factor. Its formula is $\mathrm{Br}$ by. In the reproduction the bands and tip of the abdomen are too black. They should be more like fig. 2 and the yellow should be more saffron. This fly was not used in these experiments. 

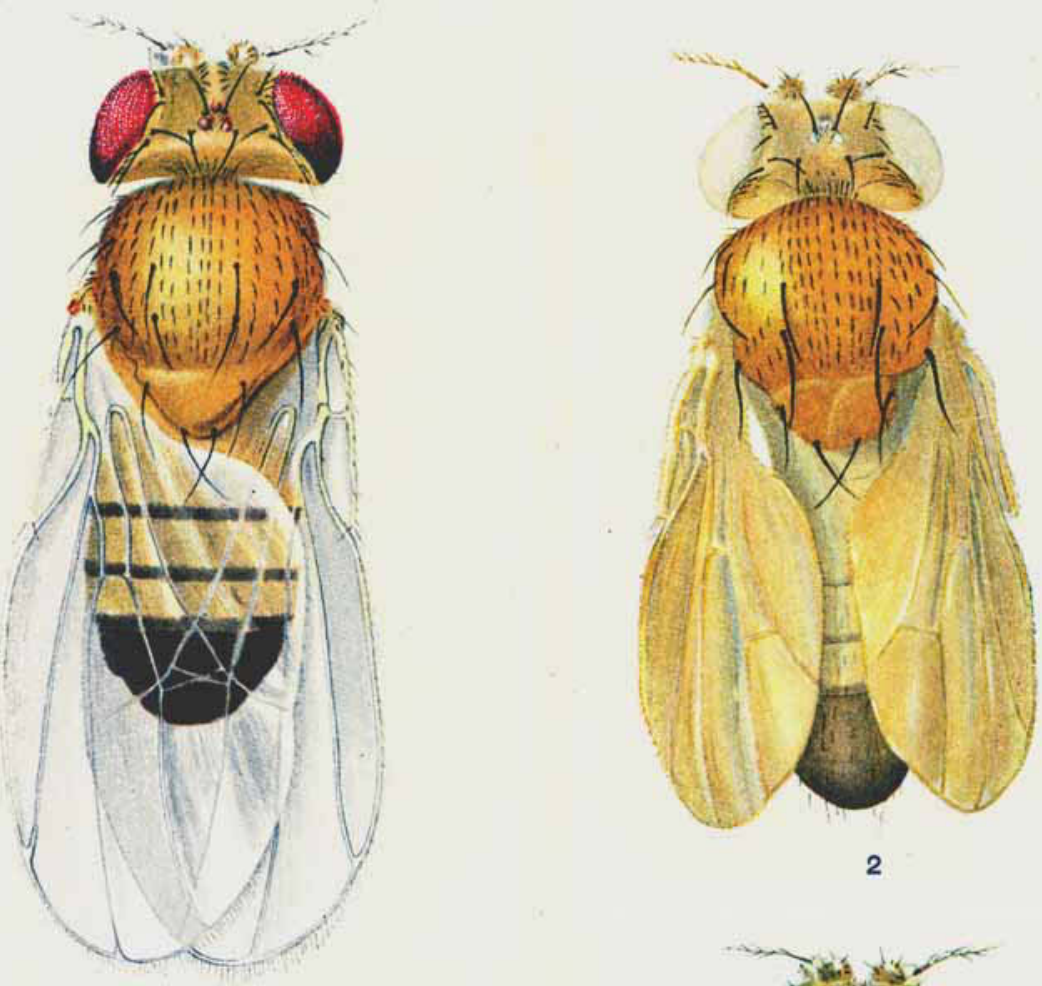

2
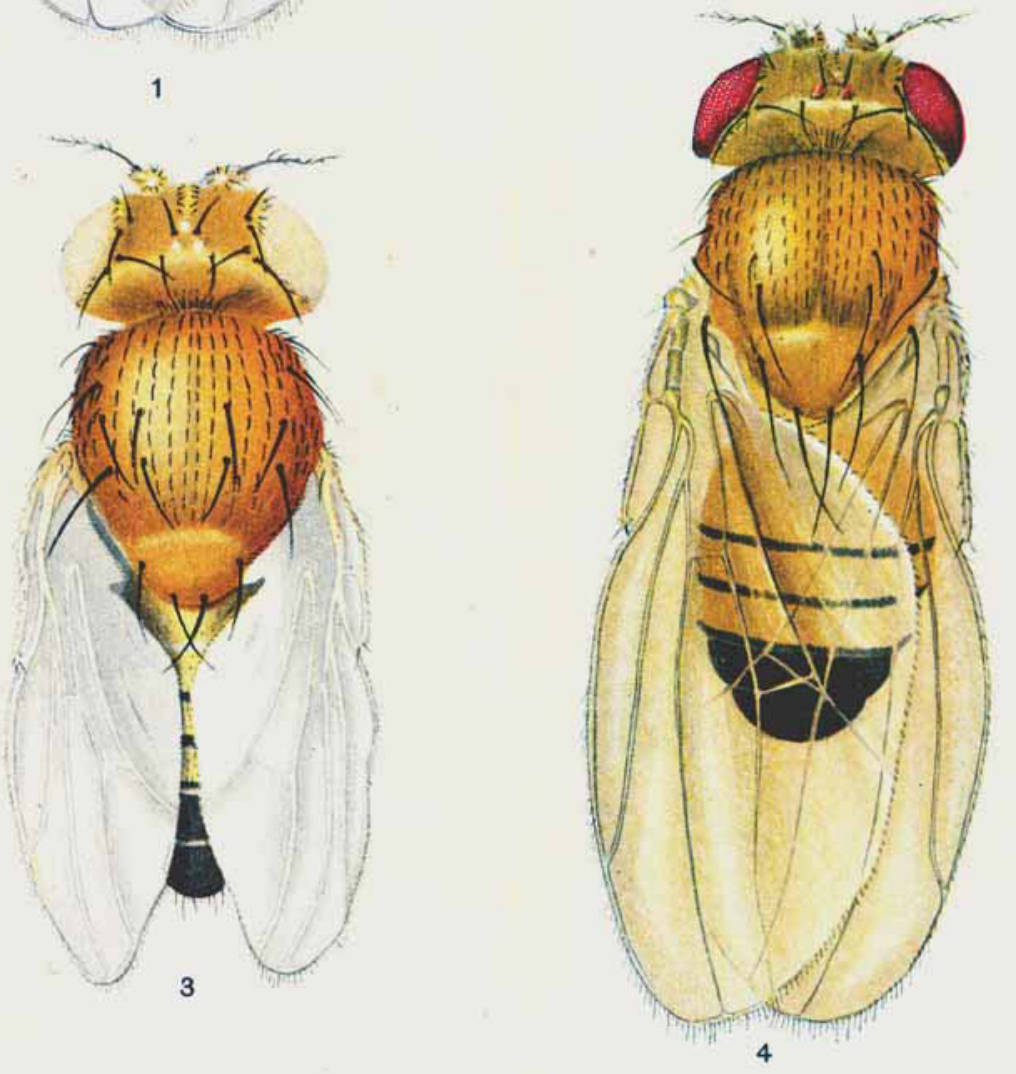

THE JOURNAL OF EXPERIMENTAL ZOOLOGY, YOL. 11, No. 4.

E. M. Wallace and M. B. Abbott, Del. 